\title{
Synthesis of a Microporous Layered Titanium Phenylphosphonate in Presence of Sodium Dodecylsulfate
}

\author{
Nawal Kishor MAL, Masahiro FUJIWARA, Yusuke YAMADA, \\ Koji KURAOKA and Masahiko MATSUKATA* \\ National Institute of Advanced Industrial Science and Technology, AIST Kansai, 1-8-31, Midorigaoka, Ikeda-shi, Osaka 563-8577 \\ *Department of Applied Chemistry, Waseda University, 3-4-1, Okubo, Shinjuku-ku, Tokyo 169-8555 \\ ドデシル硫酸ナトリウム存在下でのミクロポーラスな層状フェニルリン酸チタンの合成 \\ Nawal Kishor MAL·藤原正浩 $\cdot$ 山田裕介・藏岡孝治·松方正彦* \\ 産業技術総合研究所関西センター, 563-8577 池田市緑丘 1-8-31 \\ *早稲田大学理工学部, 169-8555 東京都新宿区大久保 3-4-1
}

\begin{abstract}
Microporous layered titanium phenylphosphonate, $\mathrm{Ti}\left(\mathrm{O}_{3} \mathrm{PC}_{6} \mathrm{H}_{5}\right)_{2}$ and sulfonated titanium phenylphosphonate, $\mathrm{Ti}\left(\mathrm{O}_{3} \mathrm{PC}_{6} \mathrm{H}_{4} \mathrm{SO}_{3} \mathrm{H}\right)_{0.89}\left(\mathrm{O}_{3} \mathrm{PC}_{6} \mathrm{H}_{5}\right)_{1.1} \cdot 1.8 \mathrm{H}_{2} \mathrm{O}$ were prepared in the presence of sodium dodecylsulfate (SDS). Interplanar spacing $\left(d_{001}\right)$ of titanium phenylphosphonate is $1.43 \mathrm{~nm}$ and after sulfonation it increased to $1.64 \mathrm{~nm}$. The surface area of titanium phenylphosphonate is $264 \mathrm{~m}^{2} \mathrm{~g}^{-1}$.
\end{abstract}

[Received January 14, 2003; Accepted March 24, 2003]

Key-words : Microporous material, Layered, Titanium phenylphosphonate, Sulfonation

\section{Introduction}

Following the discovery of layered zirconium phenylphosphonate, $\mathrm{Zr}\left(\mathrm{O}_{3} \mathrm{PC}_{6} \mathrm{H}_{5}\right)_{2}$, in 19781) and after the determination in $1993^{2)}$ that its structure is similar to that of $\alpha$-zirconium phosphate, $\left[\mathrm{Zr}^{\mathrm{IV}}\left(\mathrm{O}_{3} \mathrm{P}-\mathrm{OH}\right)_{2} \cdot \mathrm{H}_{2} \mathrm{O}\right]$ or $\left[\mathrm{M}^{\mathrm{IV}}\left(\mathrm{O}_{3} \mathrm{P}-\right.\right.$ $\mathrm{R})_{2}$. solvent] (where $\mathrm{R}=$ alkyl, aryl, alcoholic, amino, carboxylic, sulfonic, etc., and solvent are intercalated molecules, when present), the chemistry of layered metal (IV) phenylphosphonate, $\mathrm{M}^{\mathrm{IV}}\left[\left(\mathrm{O}_{3} \mathrm{PC}_{6} \mathrm{H}_{5}\right)_{2}\right]$ was greatly extended (studied). ${ }^{1-9)}$ Recently, the nonhydrolytic sol-gel route was reported as effective in the preparation of layered $M$ (IV) phenylphosphonates (where $\mathrm{M}=\mathrm{Si}, \mathrm{Zr}$, Ti and $\mathrm{Sn}$ ) and no information of porosity was provided. ${ }^{10)}$ Organic derivatives of $\gamma-\mathrm{ZrP}\left[\mathrm{Zr}\left(\mathrm{O}_{3} \mathrm{P}-\mathrm{OH}\right)_{2} \cdot 2 \mathrm{H}_{2} \mathrm{O}\right]$ have been prepared by interexchange reactions with phenylphosphonic acid where the dihydrogen phosphate group of $\gamma-\mathrm{ZrP}$ is partially replaced by the organic phosphonate. ${ }^{11,12)}$ Some of these have practical applications and are investigated as hosts in intercalation compounds, ion exchangers, photochemical reactions, molecular recognition materials and catalyses, adsorbents for gas separations, and electrochemical devices such as solid state gas sensors. ${ }^{3), 8), 13), 14)}$ In addition, these materials show good thermal stability. ${ }^{8)}$ Sulfonated zirconium phenylphosphonate is known as a strong BrOnsted acid catalyst (higher than zeolite $\mathrm{Y}$ and HZSM-5), an excellent proton conductor ${ }^{3)}$ and a very effective catalyst for a number of organic reactions including the conversion of oximes, semicarbazones and tosylhydrazones to their respective carbonyl compounds. ${ }^{15), 16)}$

Layered titanium (IV) phenylphosphonate $\left[\mathrm{Ti}^{\mathrm{IV}}\left(\mathrm{O}_{3} \mathrm{P}-\right.\right.$ $\left.\mathrm{C}_{6} \mathrm{H}_{5}\right)_{2}$ ] gives the solid with mesoporosity in character and hysteresis. ${ }^{5), 6), 9)}$ Mesoporosity arises from the adsorption of interparticles and the loss of phenylphosphonate ions due to their hydrozable nature. ${ }^{9)}$ Here, we report, for the first time, the synthesis of microporous (without any mesoporosity) layered titaniumphenylphosphonate, $\mathrm{Ti}\left(\mathrm{O}_{3} \mathrm{PC}_{6} \mathrm{H}_{5}\right)_{2}$ and sulfonated derivative in the presence of sodium dodecylsulfate (SDS) in aqueous media.

\section{Experimental}

In a typical method, $0.015 \mathrm{~mol}$ of $\mathrm{TiCl}_{4}(15 \mathrm{~g}, 1 \mathrm{M}$ in tol- uene, Aldrich.) was added to $0.03 \mathrm{~mol}$ of phenylphosphonic acid (4.99 g, 95\%, Wako Chem.) in $70 \mathrm{~g}$ of $\mathrm{H}_{2} \mathrm{O}$ under vigorous stirring. $9 \mathrm{mmol}$ of $\mathrm{SDS}(2.73 \mathrm{~g}, 95 \%$, Wako Chem.) was then added and stirred for $40 \mathrm{~min}$. Finally, gel was transferred into a Teflon-lined stainless-steel autoclave and heated statically at $423 \mathrm{~K}$ for $36 \mathrm{~h}$. The final product was filtered, washed with distilled water, and dried at $393 \mathrm{~K}$ for 1 day. Surfactant was removed by stirring the mixture of $1 \mathrm{~g}$ of titanium phenylphosphonate with $50 \mathrm{~g}$ of dry ethanol and $3 \mathrm{ml}$ of $\mathrm{HCl}(1 \mathrm{M})$ at $333 \mathrm{~K}$ for $2 \mathrm{~h}$. Finally, the product was filtered, washed with ethanol and dried at $393 \mathrm{~K}$ for 1 day and is referred to as Sample 1. For comparison, Samples 2 and 3 were prepared according to the procedure described by Villa-Garcia et al. ${ }^{6}$ In a typical synthesis of sample 2, $3 \mathrm{~g}$ of $\mathrm{TiCl}_{4}$ in $20 \mathrm{~g}$ of distilled water was added to $60 \mathrm{ml}$ of a $1 \mathrm{M}$ solution of phenylphosphonic acid while heating at $373 \mathrm{~K}$ for $2 \mathrm{~h}$. The resultant solid was also washed with distilled water (until $\mathrm{pH}=4$ ) and then air dried at $323 \mathrm{~K}$. Sample 3 was prepared by reacting $60 \mathrm{ml}$ of a $1 \mathrm{M}$ solution of phenylphosphonic acid with $25 \mathrm{ml}$ of a solution of $\mathrm{TiCl}_{3}(0.5 \mathrm{M})$. The reaction mixture was treated at $353 \mathrm{~K}$ for 7 days. Finally, the product was filtered, washed and dried at $323 \mathrm{~K}$. Sample 4 was prepared by slow decomposition of a titanium(IV) fluorocomplex in the presence of phenylphosphonic acid, following the procedure described by Dines and Digaicomo. ${ }^{5}$ The phenyl group was readily sulfonated. ${ }^{3)}$ The sulfonation reaction was carried out by adding $3 \mathrm{~g}$ of Sample 1 ( $8.34 \mathrm{mmol})$ to $17 \mathrm{mmol}$ of fuming sulfuric acid (15.13 g, 20\%, Aldrich Chem.). The mixture was kept at $348 \mathrm{~K}$ for $1 \mathrm{~h}$. $\mathrm{H}_{2} \mathrm{O}$ was added dropwise to convert the excess $\mathrm{SO}_{3}$ to $\mathrm{H}_{2} \mathrm{SO}_{4}$ followed by the addition of 100 $\mathrm{ml}$ of methanol and then the sample was centrifuged. Elemental analyses of the samples were carried out using ICP (Shimadzu ICPV-1017). Characterization of the samples was obtained using XRD $(\mathrm{Cu} \mathrm{K} \alpha$ radiation, $\lambda=0.15406$ $\mathrm{nm}$ ), $\mathrm{N}_{2}$ adsorption-desorption at $77 \mathrm{~K}$ (Bellsorp 28), TG-DTA (Seiko, SSC $/ 5200$, heating rate $=5^{\circ} \mathrm{C} \mathrm{min}^{-1}$ ), UV-VIS (JASCO V-560) and FT-IR (Perkin Elumer Spectrum One) using a $\mathrm{KBr}$ pellet. 


\section{Results and discussion}

Elemental analysis of Sample 1 found, $13.34 \% \mathrm{Ti}$, $39.96 \% \mathrm{C}, 2.82 \% \mathrm{H}$ and $17.20 \% \mathrm{P}$. These values are consistent with the molecular formula, $\mathrm{Ti}\left(\mathrm{O}_{3} \mathrm{PC}_{6} \mathrm{H}_{5}\right)_{2} ; 13.30 \% \mathrm{Ti}$, $40.01 \%$ C, $2.78 \%$ H, $17.23 \%$ P. The sulfonated Sample 1 gives, $10.31 \% \mathrm{Ti}, 31.06 \% \mathrm{C}, 2.94 \% \mathrm{H}, 13.35 \% \mathrm{P}$ and $6.14 \% \mathrm{~S}$, which matches the molecular formula $\mathrm{Ti}\left(\mathrm{O}_{3} \mathrm{PC}_{6} \mathrm{H}_{4}\right.$ $\left.\mathrm{SO}_{3} \mathrm{H}\right)_{0.89}\left(\mathrm{O}_{3} \mathrm{PC}_{6} \mathrm{H}_{5}\right)_{1.1} \cdot 1.8 \mathrm{H}_{2} \mathrm{O} ; 10.32 \% \mathrm{Ti}, 31.04 \% \mathrm{C}$, $2.93 \% \mathrm{H}, 13.37 \% \mathrm{P}, 6.14 \% \mathrm{~S}$. This result well agrees with TG analysis results as discussed later. In Fig. 1, XRD patterns of Samples 1, 2, 4 and sulfonated Sample 1 are shown. XRD patterns of all the samples are similar ${ }^{1), 3), 4), 6)}$ which indicates they are isostructural (have a similar structure) to $\alpha-\mathrm{Zr}\left(\mathrm{O}_{3} \mathrm{P}-\mathrm{OH}\right) \cdot \mathrm{H}_{2} \mathrm{O}^{2}{ }^{2}$ Sulfonated Sample 1 retained its crystallinity after sulfonation, i.e., intensity of the low angle peak $\left(d_{001}\right)$ remained unchanged, whereas broadening of peaks occurred between 25 and $30^{\circ}$ in comparison to parent Sample 1 (Figs. 1 (a) and (d)). When zirconium phenylphosphonate was subjected to sulfonation, its crystallinity severely decreased.3) It is clearly evident that titanium phenylphosphonate is more resistant to sulfonation in comparison to zirconium phenylphosphonate. Interplanar spacings, $d_{001}$ of Samples 1,2 and 3 are $1.43,1.45$ and $1.46 \mathrm{~nm}$, respectively, which are smaller than that of zirconium phenylphosphonate $\left(d_{001}=1.47 \mathrm{~nm}\right)^{1)}$ due to having smaller ionic radii of $\mathrm{Ti}^{4+}\{0.075 \mathrm{~nm}$, octahedral (oh) $\}$ compared with $\mathrm{Zr}^{4+}\left(0.086 \mathrm{~nm}\right.$, oh). However, $d_{001}$ of Sample 1 increased from $1.43 \mathrm{~nm}$ to $1.64 \mathrm{~nm}$ after sulfonation. Figure 2 shows the $\mathrm{N}_{2}$ adsorption-desorption isotherms of Sample 1 featuring a type-I isotherm, which is characteristic of microporous material. The pore size distribution curve calculated from the adsorption branch of the isotherm using

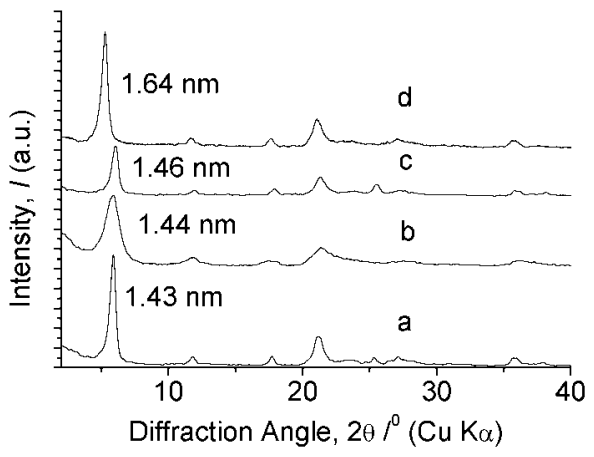

Fig. 1. XRD profiles of Sample 1 (a), Sample 2 (b), Sample 4 (c) and sulfonated Sample 1 (d).

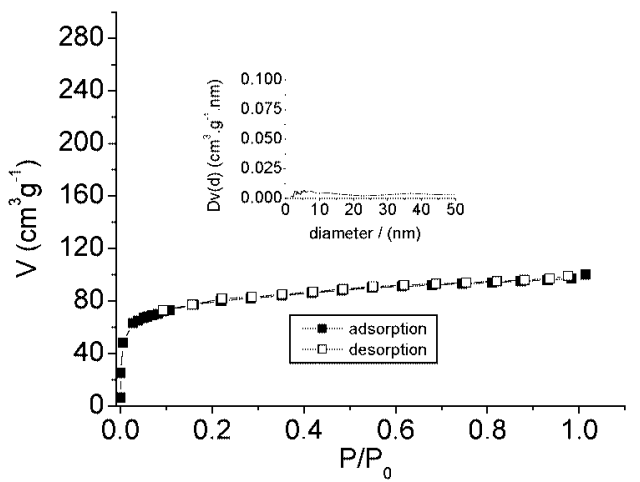

Fig. 2. $\mathrm{N}_{2}$ adsorption-desorption isotherms of Sample 1 (Inset: Pore size distribution curve).
Barrett-Joyner-Halenda (BJH) exhibits the absence of mesoporosity in Sample 1 (Fig. 2; inset). ${ }^{17)} \mathrm{N}_{2}$ adsorption-desorption isotherms of Samples 2, 3 and 4 are type IV with hysteresis loop, an indication of mesoporous materials. ${ }^{6)}$ Samples 2, 3 and 4 contain a very small amount of microporosity as there is very small adsorption at $p / p \leq$ 0.05.6) The pore size distributions of the adsorption branches of Samples 2, 3 and 4 exhibit broad pore size distributions with peak pore diameters (pore size maxima in pore size distribution curve) at $12,13.6$ and $70 \mathrm{~nm}$, respectively. ${ }^{6)}$ The porosity characteristic for all the samples are presented in Table 1. Surface area of Sample 1 is $264 \mathrm{~m}^{2} \mathrm{~g}^{-1}$. Surface area of Samples 2, 3 and 4 are 143, 61 and $79 \mathrm{~m}^{2} \mathrm{~g}^{-1}$, respectively. ${ }^{6)}$ Surface area of Sample 1 is 2- to 4-fold those of Samples 2, 3 and 4.

FT-IR spectra of Samples 1, 2 and sulfonated Sample 1 are shown in Fig. 3. Spectra of Samples 1 (after SDS removal) and 2 are similar (Figs. 3(a) and (b)). Sample 1 before SDS removal shows intense $\mathrm{CH}$ bands at 2850 and $2945 \mathrm{~cm}^{-1}$, which are absent in Sample 1, confirming the complete removal of surfactant after ethanol-acid treatment (Fig. $3(\mathrm{a})) \cdot \mathrm{H}_{2} \mathrm{O}$ and $\mathrm{OH}$ groups in Samples 1 and 2 are negligible, as a very weak band exists at approximately $3400 \mathrm{~cm}^{-1}$. The phenyl $v(\mathrm{C}=\mathrm{C})$ bands appeared at 1438 , and 693 and 749 (out of plane), and 728 , and the typical bands for these materials at $3056[v(\mathrm{C}-\mathrm{H})$ aromatic $], 1157$, 1085 and $1013 \mathrm{~cm}^{-1}[\nu(\mathrm{P}-\mathrm{O})]$ are present. $\left.{ }^{3}, 7\right)$ No band exists at approximately $924 \mathrm{~cm}^{-1}$, indicating the absence of $\mathrm{P}-\mathrm{OH}$ groups in Samples 1 and 2.7) The sulfonated product yielded several new peaks. Free $-\mathrm{OH}$ groups appeared at 3855 and $3747 \mathrm{~cm}^{-1}$. The broad band in the hydroxyl region $\left(3436 \mathrm{~cm}^{-1}\right)$ results from the presence of both SO-H and $\mathrm{H}_{2} \mathrm{O}$ stretching vibrations. Many other new peaks appeared at $1226 \mathrm{~cm}^{-1}(\mathrm{~S}-\mathrm{O})$. In addition, the phenyl ring out-ofplane bands at 693 and $804 \mathrm{~cm}^{-1}$ indicate that the ring is now meta disubstituted. ${ }^{3)}$

TG analyses of Sample 1 before and after SDS removal, Sample 4 and sulfonated Sample 1 are shown in Fig. 4. Samples 1 (before and after SDS removal) and 4 show less than $1.3 \%$ weight loss below $433 \mathrm{~K}$, indicating the absence of $\mathrm{H}_{2} \mathrm{O}$. Small weight loss (below 1.3\%) is due to physically absorbed $\mathrm{H}_{2} \mathrm{O}$ (Figs. 4(a), (b) and (c)). Sulfonated Sample 1 lost $7 \%$ (or 1.80 moles) of $\mathrm{H}_{2} \mathrm{O}$, resulting from the loss of interlayer $\mathrm{H}_{2} \mathrm{O}$ below $433 \mathrm{~K}$. Sample 1 before surfactant removal shows three distinct points of weight loss at 473 , 550 and $693 \mathrm{~K}$; the first two slopes are due to decomposition and desorption of SDS $(7.7 \%)$, respectively, and the latter (last) one is due to the loss of phenyl groups. Samples 1 (after SDS removal) and 4 show one distinct period of weight loss which starts at $693 \mathrm{~K}$ and is completed at $800 \mathrm{~K}$, being equal to $33.8 \%$, which is almost equal to the content of the phenyl group. Sulfonated Sample 1 shows four plateaus: one begins at $340 \mathrm{~K}$ (water), the second and third weight loss periods begin at 400 and $560 \mathrm{~K}$ to represent a split of either $\mathrm{SO}_{2}$ or $\mathrm{SO}_{3}$ and the fourth one represents the burning of

Table 1. Porosity of Titanium (IV) Phenylphosphonates

\begin{tabular}{lllll}
\hline Sample & $\mathrm{S}_{\mathrm{BET}} / \mathrm{m}^{2} \mathrm{~g}^{-1}$ & Peak pore diameter $/ \mathrm{nm}$ & Porosity & Reference \\
\hline Sample 1 & 264 & n.a. ${ }^{\mathrm{a}}$ & micropore & This work \\
Sample 2 & 143 & 12 & mesopore & 6 \\
Sample 3 & 61 & 13.6 & mesopore & 6 \\
Samplc 4 & 79 & 70 & mesopore & 6
\end{tabular}

n.a. = not applicable. 


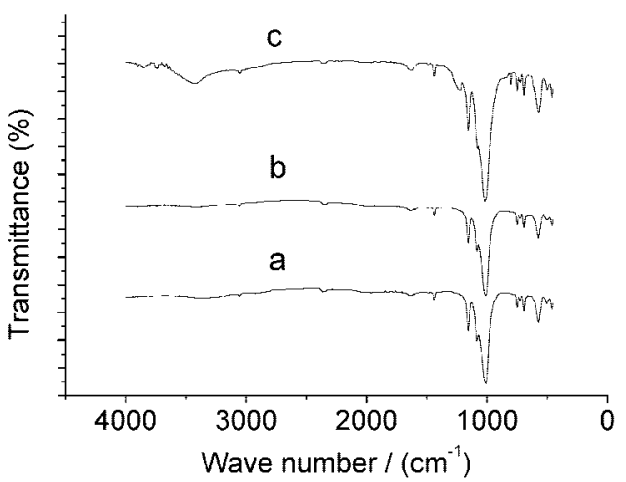

Fig. 3

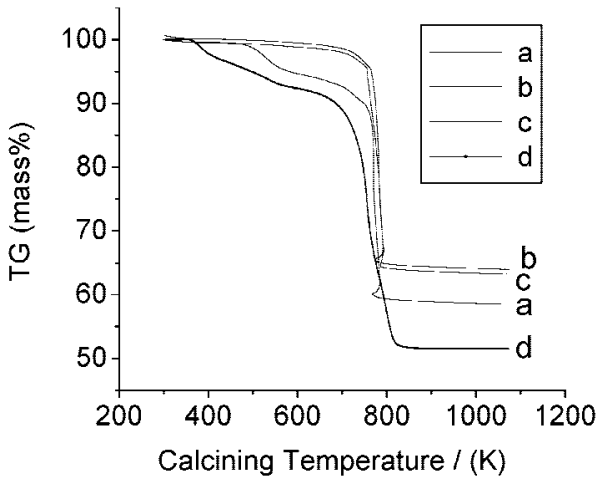

Fig. 4

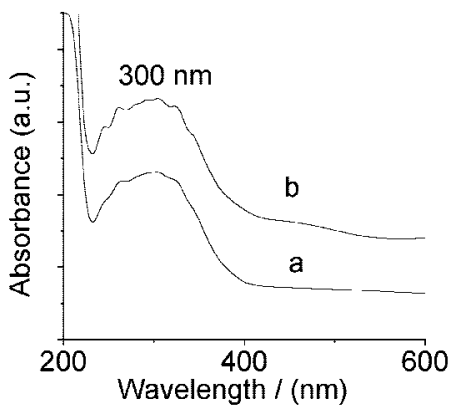

Fig. 5

Fig. 3. FT-IR spectra of Sample 1 (a), Sample 2 (b) and sulfonated Sample 1 (c).

Fig. 4. TG analyses of Samples 1, before (a) and after surfactant removal (b), Sample 4 (c) and sulfonated Sample 1 (d).

Fig. 5. UV-VIS spectra of Sample 1 (a) and Sample 2 (b).

phenyl groups. The total weight loss observed for Samples 1 (before SDS removal), 1 (after SDS removal), 4 and sulfonated 1 are $41.6,34.4,35.2$ and $48.5 \%$, respectively, whereas the expected values are 41.3, 33.6, 33.6 and $48.7 \%$, respectively. In Fig. 5, UV-VIS spectra of Samples 1 and 2 are shown. The presence of a band at approximately $300 \mathrm{~nm}$ confirms the octahedral coordination of titanium in titanium phenylphosphonate.

The micropore of Sample 1 results from interlayer space. It may be possible that SDS creates micropore voids in the layers by a growth blocking mechanism, i.e., the layers have to grow around SDS molecules, whereas in Samples 2, 3 and 4 , mesopores most likely originate due to two reasons; the end-side particle interactions, some of which could be internal pores formed by cutting layers owing to hydrolysis, and the loss of phosphonate ions because of their more hydrolysable nature. ${ }^{9)} \mathrm{Ti}^{4+}$ ions covalently bonded to six oxygens of six different phenylphosphonate groups. The phosphonate group is a tetrahedral coordinated to three oxygens and one phenyl group, therefore the phosphorous ion has a positive charge, which may hydrolyze in acidic solution. When sodium dodecylsulfate (SDS) was used, the negatively charged dodecylsulfate ions stabilize the positively charged phosphorous $\left(\mathrm{P}^{5+}\right)$ cations. It may also be possible that SDS acts as surfactant. SDS is known as a structure-directing agent (surfactant) like hexadecyltrimethylammonium bromide in the formation of the micelle and interacts with inorganic species to form uniform mesoporous inorganic materials. ${ }^{18)}$ Microporous layered titanium phenylphosphonate may exist within the mesopore, because after the calcinations at $873 \mathrm{~K}$ the obtained amorphous material is mesoporous in character. Microporous titanium phenylphosphonate may be useful as shape- and size-selective molecular sieving applications. Sulphonated microporous $\mathrm{Ti}\left(\mathrm{O}_{3} \mathrm{PC}_{6} \mathrm{H}_{4} \mathrm{SO}_{3} \mathrm{H}\right)_{0.89}$ $\left(\mathrm{O}_{3} \mathrm{PC}_{6} \mathrm{H}_{5}\right)_{1.1} \cdot 1.8 \mathrm{H}_{2} \mathrm{O}$ would be a very effective catalyst as it has strong BrOnsted acidity (greater than that of $\mathrm{ZeY}$ and ZSM-5), ${ }^{16)}$ it is a proton conductor ${ }^{2)}$ and it is shape-selective for a number of organic reactions including the conversion of oximes, semicarbazones and tosylhydrazones to their respective carbonyl compounds, like sulfonated zirconium phenylphosphonate. ${ }^{15), 16)}$

In conlusion, for the first time, microporous titanium phenylphosphonate, $\mathrm{Ti}\left(\mathrm{O}_{3} \mathrm{PC}_{6} \mathrm{H}_{5}\right)_{2}$ and sulfonated derivative, $\mathrm{Ti}\left(\mathrm{O}_{3} \mathrm{PC}_{6} \mathrm{H}_{4} \mathrm{SO}_{3} \mathrm{H}\right)_{0.89}\left(\mathrm{O}_{3} \mathrm{PC}_{6} \mathrm{H}_{5}\right)_{1.1} \cdot 1.8 \mathrm{H}_{2} \mathrm{O}$ were pre- pared in the presence of sodium dodecylsulfate. The surface area of titanium phenylphosphonate is $264 \mathrm{~m}^{2} \mathrm{~g}^{-1}$.

Acknowledgement One of the authors, N. K. Mal is grateful for receiving the STA fellowship.

\section{References}

1) Alberti, G., Costantino, U., Allulli, S. and Tomassini, N., J. Inorg. Nucl. Chem., Vol. 40, pp. 1113-1117 (1978).

2) Poojary, M. D., Hu, H.-L., Campbell III, F. L. and Clearfield, A., Acta Cryst., Vol. B49, pp. 996-1001 (1993).

3) Stein, E. W., Clearfield, A. and Subramanian, M. A., Solid State Ionics, Vol. 83, pp. 113-124 (1996).

4) Yang, C. Y. and Clearfield, A., React. Polym., Vol. 5, pp. 13-21 (1987).

5) Dines, M. B. and Digaicomo, P. M., Inorg. Chem., Vol. 20, pp. 92-97 (1981).

6) Villa-Garcia, M. A., Jaimez, E., Bortun, A., Garcia, J. R. and Rodriguez, J., J. Porous Mater., Vol. 2, pp. 85-89 (1995).

7) Jaimez, E., Bortun, A., Hix, G. B., Garcia, J. R., Rodriguez, J. and Slade, R. C. T., J. Chem. Soc., Dalton Trans., pp. 2285-2292 (1996).

8) Clearfield, A., "Progress in Inorganic Chemistry," Ed. by Karlin, K. D., John Wiley, New York (1998) pp. 371-510.

9) Pastor, P. O., Torres, P. M., Castellon, E. R. and Lopez, A. J., Chem. Mater., Vol. 8, pp. 1758-1769 (1996).

10) Corriu, R. J. P., Leclercq, D., Mutin, P. H., Sarlin, L. and Vioux, A., J. Mater. Chem., Vol. 8, pp. 1827-1833 (1998).

11) Yamanaka, S. and Hattori, M., Chem. Lett., pp. 1073-1076 (1979); Inorg. Chem., Vol. 20, pp. 1929-1931 (1981).

12) Alberti, G., "Comprehensive Supramolecular Chemistry," Vol. 7 Ed. by Alberti, G. and Bein, T., Pergamon, New York (1996) pp. 151.

13) Ogawa, M. and Kuroda, K., Chem. Rev., Vol. 95, pp. 399-438 (1995).

14) Clearfield, A., "Surface Organometallic Chemistry: Molecular Approaches to Surface Catalysis," Ed. by Basset, J. M., Kluwer Academic Publishers, Norwell, MA (1998) pp. 269-371.

15) Curini, M., Epifano, F., Marcotullio, M. C., Rosati, O. and Costantino, U., Tetrahedron Lett., Vol. 39, pp. 8159-8162 (1998).

16) Clearfield, A. and Wang, Z., J. Chem. Soc., Dalton Trans., pp. 2937-2947 (2002), and references within.

17) Barrett, E. P., Joyer, L. G. and Halenda, P. P., J. Am. Chem. Soc., Vol. 73, pp. 373-380 (1051).

18) Kresge, C. T., Leonowicz, M. E., Roth, W. J., Vartuli, J. C. and Beck, J. S., Nature, Vol. 359, pp. 710-712 (1992). 